\title{
Morphological and Vascular Study Of The Posterior Lumbar Epidural Fat
}

Frejus Sery, Esperance Broalet, Herbert Koya, Arnauld Dido

Laboratory of anatomy, Bouaké Alassane OUATTARA university, Graduate school of Medicine Bouake CÔTE D'TVOIRE. 01 BPV 18 Bouaké01; Telephone: $0022507 \quad 8391$ 59. Email: frejussery05@gmail.com

\begin{abstract}
Posterior lumbar epidural fat has been described by several authors in various fields: Anesthetic, Radiology and Neurochemistry. In this study, we tried to describe the position of this fat in the lumbar canal (L1-L5), its vascularization and drainage system. 8 Ivorian cadavers are used for the practice of dissection in the laboratory. The anterior abdominal region is chosen for the approach of the lumbar epidural region. The study investigated the situation, morphology and microcirculatory structure of fat at the lumbar level. The fatty clusters were embedded in fine vessels and were better vascularized and drained by veins of large caliber. In the vertebral canal, the fat was struck in the intervertebral foramina and was simply spread on the anterior surface of the ligamentum flavum. The fat as triangular shape with a vertebral base and a foamy summit it wanders in the cerebrospinal fluid. The lumbar epidural fat is better vascularized, and its venous drainage is made by large veins facing the intervertebral foramina embedded in areolar tissue traversed by nerve roots.

Key Words: vertebral canal, fat, structure, vascularization.
\end{abstract}

\section{INTRODUCTION}

Preferred region for lumbar punctures by pediatric physicians or anesthesiologists, the posterior lumbar epidural region is between the dural sac in front, the pedicles laterally, the blades and yellow ligament behind (Hamilton et al, 1956; Haughton et al,1980; Willimas, 1989).

It has been described for the first time by (Ramsey 1959). The latter discovered that there was in this region and at the periphery of the Dura sac, areolar tissue in which the fat was found. This fat described as semi-fluid (Beaujeux et al, 1995; Reina et al, 2009) was identified by its macroscopic and histological features. In addition to the areolar tissue situated within the epidural region, (Renard et al, 1976 and Gershater et al., 1979) described two longitudinal systems of anterior and posterior vein.

This study aimed to determine the morphology and vascular architecture of epidural fat. These findings would be useful to neurosurgeons who would try to properly expose and preserve the ductal neurovascular pedicle. For this purpose, the epidural fat was assessed by dissection of subjects embalmed.

\section{MATERIAL AND METHODS}

The dissections were performed on 8 cadavers, aged 22 to 40 years and 60 to 78 years, having been embalmed through the lumbar aorta (appendix). The lumbar vertebral columns, derived from the intervertebral discs L1-L5, were removed by anterior approach. After section of the pedicles, the posterior surface of the Dura mater was exposed. Some attachments on the pedicles, the blades and the yellow ligament were released to allow a good anatomical reading of the fat. The present study was performed on a cadaver donated to our laboratory by the morgue for student dissection and research. All procedures employed in this work complied with the ethical standards of Ivorian national guidelines on human research. 


\section{RESULTS}

In the vertebral canal, the posterior epidural fat was stuck in the inter-vertebral foramina around the nervous bundles and on the posterior surface of the Dura mater without being fixed there. It was simply spread on the anterior surface of the yellow ligament and blades in a small quantity

(Figures $1 ; 2$ ).

It was yellowish in clusters gathered together along its foramen increasingly and in the cranial caudal direction. Young subjects had a poorly compact fat, lined with a thin connective tissue extending along the posterolateral axis of the vertebral canal. Inside this canal, the fatty clusters were embedded in fine vessels and nerves and in the peridural epidural venous plexus made of regular meshes that gathered in a large vein at the entrance of the foramina (Figure 1). These clusters were fixed

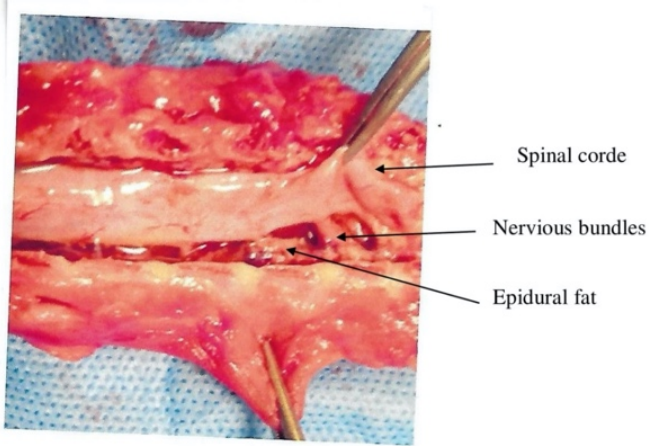

FIGURE 1: The posterior lateral Dura mater dissected from the vertebral canal. Epidural fat strucked in the intervertebral foramina around the nervous bundles.

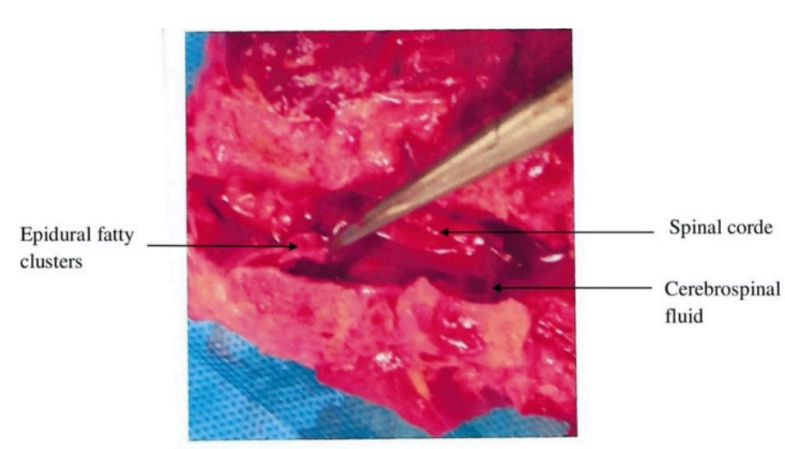

FIGURE 3 : Inside the canal, fatty clusters of the triangular shape witch a vertebral base and a foamy summit it wanders in the cerebrospinal fluid. behind by sparse areolar tissue. The morphology of this fat was clearly visible in adult subjects where it was enveloped in very dense connective tissue. Of triangular shape with a vertebral base and a foamy summit it wanders in the cerebrospinal fluid. These clusters were nonetheless detachable. Its density was significantly higher than that observed in young adults and adolescents (Figure 3).

It appeared semi-fluid on the inner surfaces of the blades and yellow ligament. The clusters next to the foramina were stronger because they were wrapped in a conjunctive membrane. Fixed next to the foramen at the exit of the nerve roots they were better vascularized and drained by veins of large caliber.

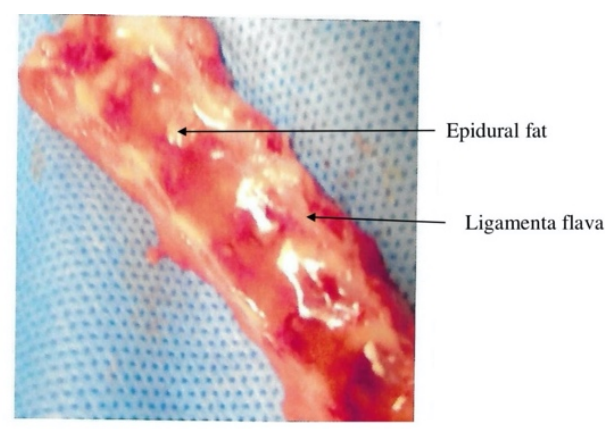

FIGURE 2 : Posterior aspect of the spinal canal with Dura mater dissected away. Epidural fat was simply spread on the anterior surface of the ligamenta flava in a small quantity

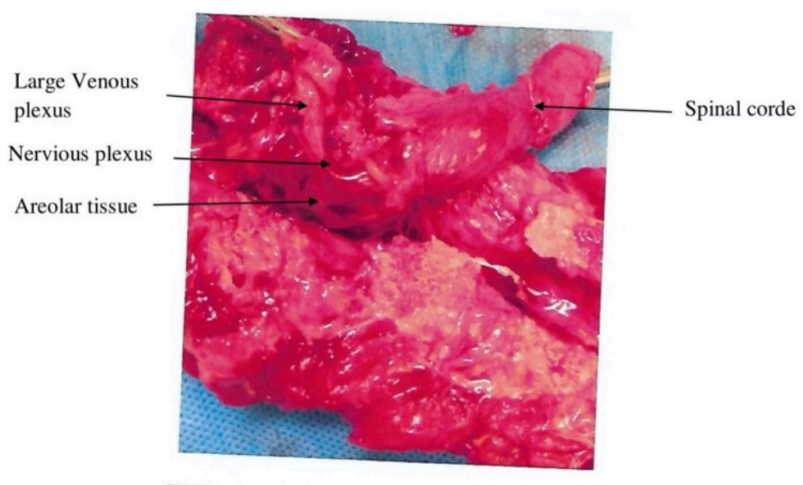

Figure 4 : The fat were better vascularized and drained veins of large calibre. 
These vessels sometimes traversed the fat horizontally, or penetrated the Dura mater, either running along its circumference or sliding along it. Some fine vessels intended for fat had a constant height between 15 and
$25 \mathrm{~mm}$ with a diagonal of up to 7.11 or even $14 \mathrm{~mm}$ (figure 4). The entire internal venous plexus was drained by large first- and secondgeneration veins embedded in fat and areolar tissue.

\section{DISCUSSION}

The epidural space is sometimes chosen for many medico-surgical manipulations including injections of anesthetic products, analgesia, drug injections of steroids for nerve pain of various origins (Digiotti, 1933; Lewit et al, 1975; Bromage, 1978; Husemeyer et al, 1980). The fat contained in the epidural cavity was localized only opposite the inter-vertebral foramina, on the yellow ligament and the posterior surface of the Dura mater (Yong-Hing et al, 1976; Zarzur, 1984; Parking et al, 1985). Our results were superimposable on those of Ramsey's dissection.

During the last decade, this fat was extensively discussed (Ramsey, 1959; Lewit et al, 1975; Gershater et al, 1979; Haughton et al., 1980; Brockstein et al, 1994) for several exploration techniques, endoscopic surgery or open surgery. These authors described little the morphology of this fat and its vascularization. Our dissection on injected subjects specified the mode of vascularization of this fat at the macroscopic level. The fat contained in the epidural cavity was located only opposite the inter-vertebral foramina, on the yellow ligament and on the posterior surface of the Dura mater. Our results were superimposable on those of (Ramsey's 1959) dissection.

We had also found areolar tissue within the fat clusters and which conferred on them the neither solid nor fluid feature. The presence of this tissue made some authors (Domisse,
1975; Parking et al, 1985; Reina et al, 2009) discuss the semi-fluid nature because it also contained an internal vertebral venous plexus, arteries and nerves. We joined in our work those of (Gershater 1979), who spoke of anterior and posterior venous system which for us, represented veins of first and second generation.

Our work was similar to those of (Renard 1976 and Gershater, 1979), who spoke of the antero-internal and antero-external system functioning together until next the intervertebral foramen were, they separated, leaving room for the nerve root.

In conclusion, although neurologically surgically important posterior epidural fat lies in a corner between the yellow ligament and the vertebral canal associated with thin areolar tissue fibers. The fat contains among others a rich vascularization with a drainage made of large veins of first and second generation with regard to intervertebral foramina. With respect to appropriate neurological surgical treatment in the vertebral canal in this region, we believe that clarification of the anatomical and vascular features of fat is helpful in determining a successful intervention.

Acknowledgements: We are grateful to those the director and the morgue staff who donated the cadavers for research and education on human anatomy without any remuneration.

Funding: This research did not receive any specified grant from funding agencies in the public, commercial, or not for profit sector.

Conflict of interest: None

\section{REFERENCES}

1. Beaujeux R, Dietemann JL, Allal R, Wolfran-Gabel R. 1995. Graisse épidurale postérieure et canal lombaire étroit: tissu de remplissage ou acteur du conflit ? Journal de Neuroradiologie $2: 63-70$.

2. Brockstein B, Johns L, Gewertz BL. 1994. Blood supply to the spinal cord: anatomic and physiology correlations. Ann Vasc Surg pp: 394-399. 
3. Bromage, PR. 1978. Epidural analgesia. Philadelphia: WB Saunders. 191-196.

4. Digliotti AM. 1933. Research and clinical observations on spinal anesthesia: with special reference to the epidural technique. Anesthesia \& Analgesia. 59-65.

5. Domisse GF. 1975. The arteries and veins of the human spinal cord from birth. Edinburgh: Churchill Livingstone $\mathrm{pp}: 81-96$.

6. Gershater, R. \& St Louis, E. L. 1979. Lumbar epidural venography. Review of 1200 cases. Radiology. 131:409-421.

7. Haughton, V.M. Syverstem, A.L. 1980. Soft tissue anatomy within the spinal canal as seen on computerized tomography. Radiology 134: 649-655.

8. Hamilton, W.J. 1956. Textbook of Human Anatomy p: 710.

9. Husemeyer RP \&White DC. 1980. Topography of the lumbar epidural space. A study in cadavers using injected polyester resin. Anesthesia. 7-11.

10. Lewit K, Sereghy T. 1975. Lumbar peridurography with special regard to the anatomy of the epidural space. Neuroradiology 8: 233-240.

11. Parking IG \& Harrison. GR. 1985. The topographical anatomy of the lumbar epidural space. Journal of Anatomy pp: 211-217.

12. Ramsey, H.J. 1959. Comparative morphology of fat in the epidural space. American Journal of Anatomy. 105: 219-232.

13. Reina MA, Franco CD, Lopez A, De Andres JA \&Zundert A. 2009. Clinical implications of epidural fat in the spinal canal. A scanning electron microscopic study. Acta Anesthesiol Blelg pp :1123-1144.

14. Renard M, Massson JP, Larde D. 2009. les veines épidurales lombaires. (étude anatomique à propos de 31 cas). Bulletin de l'Association des anatomistes 60 : 787-800.

15. Williams PL, Warwick R, Dyson M \& Bannister LH. 1989. Gray's anatomy. 37th Ed. Edinburgh: Churchill Livingstone pp : 1123-1143.

16. Yong-Hing K, Reilly J, Kirkaldy-Willis WH. 1976. The ligamenta flava. Spine pp: 226-34.

17. Zarzur E. 1984. Anatomic studies of the human ligamentum flavum. AnesthAnalg. 63:499402. 